\title{
Bidding strategy of a micro grid for the day-ahead energy and spinning reserve markets: the problem formulation
}

\author{
Gabriella Ferruzzi $^{1 *}$, Federico Rossi ${ }^{1}$, Antonio Bracale ${ }^{2}$ \\ ${ }^{1}$ Department of Industrial Engineering/University of Naples Federico II, Naples 80100, Italy \\ ${ }^{2}$ Department of Industrial Engineering/University of Naples Parthenope, Naples 80100, Italy
}

\author{
Email: gabriella.ferruzzi@unina.it
}

\begin{abstract}
The paper is addressed to the construction of an optimally bidding for a Micro Grid (MG) that takes part to both day-ahead energy and spinning reserve markets. The work shows that the decision about the amount of power to offer, related to the expected prices and different risk tolerances, must be taken contextually through a joint approach.

For that purpose, an optimization problem is formulated. In order to help the decision maker to understand the potential impact of different sub-optimal choices, the model evaluates also the risk associated with the uncertainty of variable power to offer in the both markets. The risk associated is evaluated by the expected utility theory that takes into account the attitude of individuals with regard to risk (adversion, neutrality or propensity) to make decision that minimize negative returns.

The effectiveness of the proposed model is assessed through the analysis of a MG composed by traditional power plants, combined heat and power (CHP) plants, and heat production plants (boilers). The presence of storages systems is also accounted for. Moreover, it is considered that both generators and loads can take part in the reserve market and the demand participation happens through both shiftable and curtailable loads.
\end{abstract}

Keywords: Smart Grid, Deregulated Markets, Risk Management, Optimization Problem.

\section{INTRODUCTION}

In the deregulated electricity market the negotiation process between buyers and sellers does not end in the wholesale energy market. In fact, the last step of the process is represented by the ancillary services market, in which imbalances between programmed and real flows are deleted.

The ancillary services are: frequency control, voltage support and black start. In turn, the frequency control is exercised through several levels of regulation. The UCTE (Union for the Coordination of the Transmission of Electricity) defines three types of reserve: primary, secondary and tertiary. These correspond in FERC (United State of Energy Regulatory) to regulation, spinning and not spinning reserve $[1,2]$.

The voltage support and black- start services are, in most countries, mandatory services, more suitable for purchases based on long-term contracts [3, 4].

So it is also for the primary reserve service (with the exception of the California market). Instead, the secondary and tertiary reserve services are optional services, procured by the ISO by means of hourly competitive auctions. Generally, there are separated auctions for each reserve; they are performed the day before at the actual exchange, temporally placed downstream of energy market, i.e after the last session of the adjustment market [5].

In this work, a MG is considered as participant in both of day-ahead energy and spinning reserve markets. The participation in the markets is done with the double role of consumer and producer, depending on the direction of hourly exchanged power with the upstream grid.

A low-voltage MG is characterized by a small amount of total capacity, while the market rules generally require that almost a fixed amount of energy must be offer in the reserve market. In order to respect the power limit, we assume that the bid to present into the market is a virtual aggregated bid, resulting from the offers of more microgrids (MGs), formulated by each prosumer in independent way. For this purpose, we hypothesized that an aggregator exists and acts on behalf of all.

Similar to the energy market, in the reserve market the equilibrium point between the demand and supply determines the MCP for that hour (in following called reserve market price).

The demand curve is defined by the Independent System Operator (ISO), using an appropriate risk indexes linked to the probability of occurrence of faults. The supply, dependent on the price, is the aggregate curve of the single offers of the bidders. Since the capacity is reserved and procured in advance, and the energy is dispatched in response to real time 
imbalances, any bid is characterized by two different prices: the first one $(\mathrm{E} / \mathrm{MW})$ for reserved capacity and the second one (E/MWh) for dispatched energy [2, 6, 7, 8].

The objective of this paper is to show how the MG develops an optimal coordinated bidding strategy for the day-ahead energy and spinning reserve markets, evaluating different $\mathrm{MG}$ risk tolerances (adverse, neutral and incline).

The focus is the formulation of an appropriate mathematical optimization model written in a general and complete manner. It, in fact, considers a MG in which both thermal and electrical loads must be satisfied, so that in the MG only electricity power plants, combined heat and power (CHP) plants, and heat production plants (boilers) are already installed.

The presence of thermal and electrical storage systems is also accounted for. Moreover, it is considered that both generators and loads can participate in the reserve market.

The demand participation happens through both shiftable and curtailable loads [9].

The remaining of the paper is organized as follows: bidding strategy is discussed in section II and formulated in section III; discussion and conclusion are presented in final section.

\section{THE BIDDING STRATEGY AND LITERATURE REVIEW}

In [10] is shown how the MG submits, in the day-ahead energy market, bidding curves price-quantity consistent with the results obtained by the optimal management problem $[11$, 12]. In this work, indeed, the bidding strategy is limited to the submission, in the day-ahead energy and reserve markets, of the only one value of the optimal hourly powers exchanged with main grid, obtained in correspondence to the most probably hourly market price profiles.

The participation also in the reserve market introduces an additional level of complexity in the MG operation, but offers the potential for additional revenue.

From the MG's point of view, the energy and the spinning reserve markets are interdependent: in fact, as more power is produced for the energy market, as less it can be produced for the reserve market, and vice-versa.

That can imply to "withhold" capacity to offer into the energy market and reduce the quantity to offer it into reserve market, or reduce capacity into the energy market and grow up capacity to offer it into reserve market.

The decision about how much power is to be allocated in each market and at what price, must be taken a priori and contextually, that is through a joint approach. To split the decision time, namely to wait for the outcomes of the energy market and to offer, according to a sequential approach, in reserve market only the eventually residual capacity, does not optimize the MG operation.

So, a joint model must explicitly consider, among decision variables, the powers - those exchanged with the main grid and those generated by each unit, and the curtailable loads, for both markets.

These decision variables are added to the shiftable loads and to the levels and powers of the storages.

The participation of the reserve market involves that the benefits for MG can increase.

The amount of the additional revenues depend on the way in which reserve payments are made. More specifically, there are markets in which the reserve power is paid at reserve price, only when reserve is actually used. In others, the reserve power is paid, at reserve price, when reserve is allocated but not used, and, at energy price, when the reserve is used $[13,14,15]$.

Moreover, in this paper, we assume that a "perceived probability", " $\mathrm{r}_{\mathrm{t}}$ ", that reserve is called, is equal to 0 (MG does not take part in reserve market) or to 1 (the MG takes part in the reserve market).

The perceived probability is related to the density of probability that the reserve is called, obtained by analyzing historical series, different from hour to hour; moreover, it is related to a threshold value that $\mathrm{MG}$ assumes according to its propensity/adversity to risk.

In the problem there are, thus, three sources of uncertainty: the first one is linked to the not programmable renewable generation; the second to the market prices and the third just to the density of probability that reserve will be called to produce.

The problem considered in this paper was dealt with in literature almost always from the point of view of traditional generation companies (GENCOs), using sequential models $[16,17,18,19,20,21]$ or joint model $[13,14,15,22,23,24$, $25,30]$.

However, papers that address the problem with reference to VPPs or MGs are not lacking in literature [26, 27, 28, 29]. We underline that none of the last citated works formulate, as in this work, a model that allows to deal with together the cases of the call and of the not call the reserve (this is particularly relevant if inter-temporal constraints exist, as those introduced by shiftable loads and storage systems). Furthermore, none of the citied works considers the cogeneration and none treats shiftable loads.

\section{METHODOLOGY}

The proposed methodology focuses on solving ED problem consists in the development of a bidding algorithm for MGs. Our approach is organized in the following steps.

First step: the evaluation of uncertainty of reserve market calling.

The uncertainty of reserve market calling is estimated being the main limiting factor for the participation of a MG in the Day-Ahead market [3]. The Storical Series methodology is considered to estimate this uncertainty: by historical Series data, in fact, it is possible determinate a probabilistic density function (pdf) about the possibility that the reserve would be called. A threshold is established to determinate if MG can partecipate to the reserve market or not. In order to esplicitate these voluntaries, a binary variable is inserted into the model: if MG takes part to the market, the variable will be equal to 1 , differently it will be equal to 0 .

Second Step: the optimization process and implementation of model

Under the hypothesis loads are known, model outcomes become the exchanged power distribution grid and the production from DERs.

Moreover, the risk associated with the uncertainty of variable market price is analyzed to understand the potential impact of different sub-optimal choices.

There are different ways to evaluate the risk associated with a decision [22]. In this work expected utility theory is used [18, 30].

This theory evaluates the choices privileging outcomes with the highest expected utility rather than with the highest expected value. The expected utility theory takes into account 
the attitude of individuals with regard to risk (adversion, neutrality or propensity) to make decision that minimize negative returns [23]. According to this approach, for each possible outcome $\mathrm{x}$ a certain value is assigned on the basis of the individual's utility function $\mathrm{u}(\mathrm{x})$. The expected utility is obtained as average weighted utilities associated with each possible outcome probability [15, 24, 27, 28], where each weight is determined by the respective outcome probability.

The input/output from both two steps are used to determine the optimal bids to present in the Day-Ahead market $[6,17]$. In terms of optimization model, the main original contribution provided by the Authors is linked to the methodology proposed and evaluation of the risk associated with the uncertainty of variable market price.

Weight coefficients $\left(\varphi_{1}\right.$ and $\left.\varphi_{2}\right)$ are introduced by the Authors into the model with the aim to recognize the overproduction or underproduction status. The applied methodology helps the decision maker of MG to realize the potential impact of a wrong decision.

\section{THE MODEL}

The optimal management problem consists in researching, hour-by-hour during the day, the values of energy exchanged with the main distribution network, the energy production of each dispatchable unit, and the controllable load profiles that optimize an economic objective. Also the choices of the thermoelectric units that must be in operation on an hourly base and the determination of the internal network status consistent with operating constraints are part of the problem.

But, as it is considered in [10], in deriving the offers to present in the market, can be opportune to solve only the subproblem that considers the internal electrical network of the MG as a busbar and that assumes all production units are in operation.

It is assumed that: all different production units (generators and co-generators, as well as the curtaibles loads) have the requirements to provide reserve service; the load shedding is used also for the energy market; the MG can estimate fixed loads, RES production, and prices of energy and spinning reserve markets for each hour through the analisys of time series; the MG knows the density of probability that the reserve will be called to produce, which, according to [25], and contrary to $[13,14,15]$, has different values from hour to hour.

\section{Objective function}

The revenues, $\mathrm{R}$, are related to energy sold in the reserve market and, if there is, in the energy market. Neglecting the management costs of storage and shifting, the costs, $\mathrm{C}$, are related, instead, to the energy bought from the main grid, if there is, to production costs of generators, cogenerators and boilers and, finally, to load shedding.

That said, assuming that the exchanged power in the energy market is positive if it is bought and negative if it is sold, and assuming that the energy market price is equal inthe buying and selling phases, the objective function to maximize is:

$$
\begin{aligned}
& E(R-C)=\sum_{t=1}^{24} r_{t} \rho_{t}^{r} P_{g r i d_{t}}^{r}+\sum_{t=1}^{24} \rho_{t}^{e} P_{g r i d_{t}}^{e}-\sum_{t=1}^{24}(1- \\
& \left.r_{t}\right)\left[\sum_{j \in \Omega_{c}} C_{C_{j}}\left(P_{C_{e_{t, j}}}^{e}\right)+\sum_{j \in \Omega_{B}} C_{B_{j}}\left(P_{B_{t, j}}\right)+\right. \\
& \left.\sum_{j \in \Omega_{G}} C_{G_{j}}\left(P_{G_{e_{t, j}}}^{e}\right)+\sum_{j \in \Omega_{D_{C U}}} C_{D_{C U}}\left(P_{D_{C U_{t, j}}}^{e}\right)\right]- \\
& -\sum_{t=1}^{24} r_{t}\left[\sum_{j \in \Omega_{c}} C_{C_{j}}\left(P_{C_{e_{t, j}}^{e}}^{e}+P_{C_{r_{t, j}}}^{r}\right)+\sum_{j \in \Omega_{B}} C_{B j}\left(P_{B_{t, j}}\right)+\right.
\end{aligned}
$$

$$
\begin{aligned}
& \sum_{j \in \Omega_{G}} C_{G_{j}}\left(P_{G_{t, j}}^{e}+P_{G_{t, j}}^{r}\right)+\sum_{j \in \Omega_{D_{C U}}} C_{D_{C U_{j}}}\left(P_{D_{C U_{t, j}}}^{e}+\right. \\
& \left.\left.P_{D_{C U_{t, j}}}^{r}\right)\right]
\end{aligned}
$$

The first term of (1) represents the revenue, $\mathrm{R}$, from the participation to the reserve market, supposing that the reserve power is paid, at reserve price, only when reserve is actually used.

If, moreover, the reserve power is paid, at reserve price, when reserve is allocated but not used, and, at energy price, when the reserve is used, it must be changed in:

$E\left(R^{r}\right)=\sum_{t=1}^{24}\left(1-r_{t}\right) \rho_{t}^{r}+r_{t} \rho_{t}^{e} P_{g r i d_{t}}^{r}$

" $r_{t}$ " is a binary variable that id equal to 0 if MG does not take part to reserve market, or 1 if it takes.

The $r_{t}$ value is related to the density of probability that reserve is called, obtained by historical series, different from hour to hour.

In order to evaluate the "total power" to offer in the reserve market taking into account the propensity/adversity to the risk, a weight is inserted in the function:

$P_{t, j}=\left[\sum_{t=1}^{13}\left(\varphi_{1}\left(P_{t}^{e}\left(\rho_{t}^{e}\right)-P_{e k}^{e}\right)+\sum_{t=1}^{13}\left(\varphi_{2}\left(P_{t}^{r}\left(\rho_{t}^{r}\right)-\right.\right.\right.\right.$ $\left.\left.P_{e k}^{r}\right)\right]$

$0 \leq\left(P_{t}^{e}+P_{t}^{r}\right) \leq P_{e_{j}}^{M}$

The last term represents the difference between the expected value of the reserve power and the season reserve values in the same hour.

$\varphi_{1}$ and $\varphi_{2}$ take into account the difference $\left(P_{t}^{e}\left(\rho_{t}^{e}\right)-P_{e k}\right)$, in the wholesale and reserve markets, respectively.

The introduced weight assumes different values in under production and over production cases.

$\varphi_{1}=g_{u p}\left(P_{t}^{e}\left(\rho_{t}^{e}\right)-P_{e k}^{e}\right)$ if $P_{t}^{e}>P_{e k}^{e}$

$\varphi_{1}=g_{\text {down }}\left(P_{t}^{e}\left(\rho_{t}^{e}\right)-P_{e k}^{e}\right)$ if $P_{t}^{e}<P_{e k}^{e}$

The function $g_{u p}$ and $g_{\text {down }}$ are built as traditional functions of demand and supply in the market. It is important consider them into the model because several countries have in place legislation requiring power producers to pay penalties proportional to the errors of the reserve forecast, which makes the accuracy of such prediction a determining factor for producer their economic losses.

Constraints

The basic equality constraints are the thermal and electric balance constraints. Assuming that the storage powers are positive during the discharge and negative during the charge, they are the fixed loads, for each interval, is curtailed by RES production:

$$
\begin{aligned}
& \left(1-r_{t}\right)\left(\sum_{j \epsilon \Omega_{C}} \frac{P_{C_{e_{t, j}}}^{e}}{\eta_{j}}+P_{B_{e_{t, j}}}\right)+r_{t}\left(\sum_{j \epsilon \Omega_{C}} \frac{P_{C_{e_{t, j}}}^{e}}{\eta_{j}}+\right. \\
& \left.\sum_{j \epsilon \Omega_{C}} \frac{P_{C_{e_{t, j}}}^{r}}{\eta_{j}}+P_{B_{e_{t, j}}}\right)=\sum_{j \epsilon \Omega_{D_{t h}}} P_{D_{t h}, j}+\sum_{j \epsilon \Omega_{S T}} P_{S T_{t, j}} \\
& \quad\left(1-r_{t}\right)\left(\sum_{j \epsilon \Omega_{C}} P_{C_{e_{t, j}}}^{e}+\sum_{j \in \Omega_{G}} P_{G_{t, j}}^{e}+P_{g r i d_{t}}^{e}-\right. \\
& \sum_{j \in \Omega_{D_{F}}} P_{F_{t, j}}-
\end{aligned}
$$


$\left.\sum_{j \in \Omega_{D_{S H}}} P_{D_{C U}, j}^{e}+\sum_{j \epsilon \Omega_{S H}} \quad P_{D S H_{t, j}} \quad \sum_{j \epsilon \Omega_{S E}} P_{S E}^{e}{ }_{t, j}\right)+$ $r_{t}\left(\sum_{j \in \Omega_{C}} P_{C_{e_{t, j}}}^{e}+P_{C_{e_{t, j}}}^{r}+\sum_{j \in \Omega_{G}} P_{G_{t, j}}^{e}+P_{G_{t, j}}^{r}+P_{g r i d_{t}}^{e}+\right.$ $P_{\text {grid }_{t}}^{r}-\sum_{j \in \Omega_{D_{F}}} P_{F_{t, j}}-$

$\left.\sum_{j \in \Omega_{D_{S H}}} P_{D_{C U_{t, j}}}^{e}+P_{D_{C U_{t, j}}}^{r} \sum_{j \in \Omega_{S H}} P_{D_{S H_{t, j}}}+P_{S E_{t, j}}\right)$

In (3), $P_{D_{S H}, j}$ is the shifted power of the $\mathrm{j}^{\text {th }}$ shiftable load.

As shown in [30], the relationship between the loads before and after shifting can be represented by introducing binary variables $u_{t, j}$.

The condition $u_{t, j}=1$ identifies the initial interval $\mathrm{t}$ where the $j_{t h}$ shiftable load starts to be supplied for the next $S_{j}$ hours. Considering that the profile of the jth shiftable load starts only once, only a binary variable can be equal to one. Moreover, only the first $\left(T_{j}-S_{j}+1\right)$ binary variables can be defined because each $u_{t, j}$ variable is associated with the next $\left(S_{j}+1\right)$ variables $P_{D S H}, j$

It must happen that:

$\sum_{t=1}^{T_{j}-S_{j}+1} u_{t, j}=1$

Then, let us consider that only the variables associated with $u_{t, j}=1$, i.e. $P_{D S H_{t, j}}, P_{D S H} t+1, j, \ldots, P_{D S H_{t+k, j}}$ assume positive values. Specifically, each $P_{D S H}, j$ with $\mathrm{k}=\mathrm{t}-\mathrm{s}+1$, assumes the value $D_{S H-k+1, j}$.

This way, the links between shiftable and shifted loads are:

$P_{D_{S H_{t, j}}}=\sum_{S=1}^{t} D_{S H(t-k+1), j} \cdot u_{k, j}$

Additional equality constraints can be derived, then, from modeling of the storage units. In fact is necessary to express: -the variation of the storage levels:

$W_{S E_{t, j}}=W_{S E_{(t-1), j}}+P_{S E_{t, j}}$

$W_{S T_{t, j}}=W_{S T_{(t-1), j}}+k_{S, j} P_{S T_{t, j}}$

-the restoration of the storage levels:

$\sum_{t=1}^{24} P_{S E_{t, j}}=0$

$\sum_{t=1}^{24} P_{S T_{t, j}}=0$

Finally, the following inequality constraints must be considered:

- limits on cogenerators production:

$$
\begin{aligned}
& 0 \leq P_{C_{e_{t, j}}}^{r} \leq\left(P_{C_{e_{t, j}}}^{M}+P_{C_{e_{t, j}}}^{e}\right) \\
& P_{C_{e_{t, j}}}^{e}+P_{C_{e_{t, j}}}^{r} \leq P_{C_{e_{j}}}^{M}
\end{aligned}
$$

- limits on boilers production:

$$
P_{B_{j}}^{m} \leq P_{B_{t, j}} \leq P_{B_{j}}^{M}
$$

- limits on generators production:

$$
\begin{aligned}
& 0 \leq P_{G_{t, j}}^{r} \leq\left(P_{G_{j}}^{M}+P_{G, j}^{e}\right) \\
& P_{G_{t, j}}^{e}+P_{G_{t, j}}^{r} \leq P_{G}^{M}{ }_{j}
\end{aligned}
$$

- limits on curtailable loads:

$-P_{D_{C U_{t, j}}}^{M} \leq P_{D_{C U_{t, j}}}^{r} \leq 0$

$P_{D_{C U_{t, j}}}^{e}+P_{D_{C U_{t, j}}^{r}}^{r} \leq P_{D_{C U_{t, j}}^{M}}^{M}$

- $\quad$ limits on exchanged power:

$-P_{\text {grid }}^{M} \leq P_{D_{\text {grid }}}^{r} \leq 0$

$-P_{\text {grid }^{M}}^{M} \leq P_{\text {grid }_{t}}^{e}+P_{D_{\text {grid }_{t}}^{r}} \leq P_{\text {grid }}^{M}$

- limits on storage levels:

$0 \leq W_{S E_{t, j}} \leq W_{S E_{j}}^{M}$

$0 \leq W_{S T_{t, j}} \leq W_{S T_{j}}^{M}$

- $\quad$ limits on storage powers:

$P_{S E_{j}}^{m} \leq P_{S E_{t, j}} \leq P_{S E_{j}}^{M}$

$P_{S T_{j}}^{m} \leq P_{S T_{t, j}} \leq P_{S T_{j}}^{M}$

It is noted that the model does not evaluate the arbitrage opportunities: MG cannot buy more energy in the energy market to sell more into the reserve market. If arbitrage is admitted, the constraints (10) and (13) must be written as:

$0 \leq P_{C e_{t, j}}^{r} \leq\left(P_{C e_{j}}^{M}-P_{C e_{j}}^{m}\right)$

$0 \leq P_{G_{t, j}}^{r} \leq\left(P_{G_{j}}^{M}+P_{G, j}^{m}\right)$

Mathematically the problem is a non linear mixed integer programming problem. However, if the shiftable loads are not taken into account, it becomes an easier non linear programming problem.

\section{CONCLUSIONS}

This paper focused on the participation of a microgrid in both day-ahead energy and reserve spinning market.

It was shown how the $\mathrm{MG}$ solves a decision-making problem about the development of an optimal bidding strategy for both markets, evaluating different risk tolerances (adverse, neutral and incline). The strategy was based on the consideration that the decision about how much power is to be offered in each market, and at what price, must be taken a priori and contextually, namely through a joint approach.

The model was written in a general and complete way. It, in fact, considered a MG in which both thermal and electrical loads must be satisfied, so that in the MG only electricity power plants, combined heat and power (CHP) plants, and heat production plants (boilers) were already installed. The 
presence of thermal and electrical storage systems is also accounted for. Moreover, it was considered that both generators and loads can take part in the reserve market.

The demand participation happens through both shiftable and curtailable loads.

In this work, the bidding strategy is limited to the submission, in the day-ahead energy markets, of the only one value of the optimal hourly powers exchanged with the main grid, obtained in correspondence to the most probably hourly market profiles.

Future reserch will focus on the formulation of the optimal bidding curves to present in two markets and on the resolution of the Unit Commitment problem.

\section{REFERENCES}

[1] Wang Q., Zhang C., Ding Y., Xydis G., Wang J., Ostergaard J. (2015). Review of real-time electricity markets for integrating distributed energy resources and demand response, Applied Energy, Vol. 138, pp. 695 706. DOI: $10.1016 /$ j.apenergy.2014.10.048

[2] Swider D. (2007). Efficient scoring-rule in multipart procurement auctions for power systems reserve, IEEE Transactions on Power Systems, Vol. 22, No. 4, pp. 1717-1725. DOI: 10.1109/TPWRS.2007.907531

[3] Raineri R., Ros S., Schiele D. (2006). Technical and economic aspects of ancillary services markets in the electric power industry: An international comparison, Energy Policy, Vol. 34, No. 13, pp. 1540-1555. DOI: $\underline{10.1016 / \text { j.enpol.2004.11.015 }}$

[4] Rebours Y., Kirschen D., Trotignon M., Rossignol S. (2007). A survey of frequency, and voltage control ancillary services mdash; part ii: Economic features, IEEE Transactions on Power Systems, Vol. 22, No. 1, pp. 358-366. DOI: 10.1.1.452.7774

[5] Rossi F. (2007). Gestione dei sistemi elettrici nei mercati liberalizzati, Edizioni Scientiche Italiane, ESI. ISBN: 8849515197, 9788849515190.

[6] Nguyen D., Bao L. (2014). Optimal bidding strategy for microgrids considering renewable energy and building thermal dynamics, IEEE Transactions on Smart Grid, Vol. 5, No. 4, pp. 1608-1620. DOI: $\underline{\text { 10.1109/TSG.2014.2313612 }}$

[7] Singh H., Papalexopoulos A. (1999). Competitive procurement of ancillary services by an independent system operator, IEEE Transactions on Power Systems, Vol. 14, No. 2, pp. 498-504. DOI: $10.1109 / 59.761872$

[8] Chao R., H.p., Wilson R. (2002). Multi-dimensional procurement auctions for power reserves: Robust incentive-compatible scoring and settlement rules, Journal of Regulatory Economics, Vol. 22, No. 2, pp. 161-183. DOI: 10.1023/A:1020535511537

[9] Yao M., Hu Z., Stufentes F., Zhang N. (2015). Integrated power management of conventional units and industrial loads in China's ancillary services scheduling, Energies, Vol. 8, pp. 3955-3977. DOI: $\underline{10.3390 / \text { en } 8053955}$

[10] Ferruzzi G., Rossi F., Russo A. (2015). Determination of the prosumers optimal bids, International Journal of Emerging Electric Power Systems, Vol. 16, No. 6, pp. 537-548. DOI: $10.1515 /$ ijeeps-2015-0093

[24] Energy Systems, Vol. 24, No. 4, pp. 251-261. DOI: $\underline{10.1016 / \mathrm{S} 0142-0615(01) 00038-2}$
[11] Yuen C., Oudalov A., Timbus A. (2011). The provision of frequency control reserves from multiple microgrids, IEEE Transactions on Industrial Electronics, Vol. 58, No. 1, pp. 173-183. DOI: 10.1109/TIE.2010.2041139

[12] Bai H., Miao S., Ran X., Ye C. (2015). Optimal dispatch strategy of a virtual power, mplant containing battery switch stations in a unied electricity market, Energies, Vol. 8, No. 3, pp. 2268-2289. DOI: 10.3390/en8032268

[13] Allen E.H., Ilic M.D. (2000). Reserve markets for power systems reliability, IEEE, Transactions on Power Systems, Vol. 15, No. 1, pp. 228-233. DOI: $10.1109 / 59.852126$

[14] Attaviriyanupap P., Kita H., Tanaka E., Hasegawa J. (2002). A new profit-based unit commitment considering power and reserve generating, in: Power Engineering SocietyWinter Meeting, 2002, IEEE, Vol. 2, pp. 1311-1316. DOI: 10.1109/PESW.2002.985227

[15] Attaviriyanupap P., Kita H., Tanaka F., Hasegawa J. (2000). New bidding strategy mformulation for dayahead energy and reserve markets based on evolutionary programming, International Journal of Electrical Power and Energy Systems, Vol. 27, No. 3, pp. 157-167. DOI: 10.1016/j.ijepes.2004.09.005

[16] Chitkara P., Zhong J., Bhattacharya K. (2009). Oligopolistic competition of gencos in reactive power ancillary service provisions, IEEE Transactions on Power Systems, Vol. 24, No. 3, pp. 1256-1265. DOI: $\underline{\text { 10.1109/TPWRS.2009.2023266 }}$

[17] Jia X., Zhou M., Li G. (2006). Study on conjectural variation based bidding strategy in spinning reserve markets, International Conference on Power System Technology, pp. 1-5. DOI: 10.1109/ICPST.2006.321850

[18] Wang J., Wang X., Wu Y. (2005). Operating reserve model in the power market, IEEE Transactions on Power Systems, Vol. 20, No. 1, pp. 223-229. DOI: 10.1109/TPWRS.2004.841232

[19] Franco A., Lobato E., Rouco L., Ugedo A., FernandezCaro J., de Benito J., Chofre J., De-la Hoz J. (2003). Optimization of the Spanish market sequence by a price-taker generating firm, Power Tech Conference Proceedings, Bolohna, Vol. 2, p. 6. DOI: 10.1109/PTC.2003.1304603

[20] Ugedo A., Lobato E., Franco A., Rouco 1., FernandezCaro J., Chofre J. (2006). Strategic bidding in sequential electricity markets, IEEE Proceedings of Generation, Transmission and Distribution, Vol. 153, No. 4, pp. 431-442. DOI: 10.1049/ip-gtd:20045192

[21] Campos F.A., Munoz San Roque A., Sanchez-Ubeda E., Portela Gonzalez J. (2015). Strategic bidding in secondary reserve markets, IEEE Transactions on Power Systems, Vol. 31, No. 4, pp. 2847-2856. DOI: 10.1109/TPWRS.2015.2453477

[22] Wen F., David A. (2002). Optimally coordinated bidding strategies in energy and ancillary service markets, IEE Proceedings Generation, Transmission and Distribution, Vol. 149, No. 3, pp. 331-338. DOI: 10.1049/ip-gtd:20020211

[23] Wen F., David A. (2002). Coordination of bidding strategies in day-ahead energy and spinning reserve markets, International Journal of Electrical Power and

[25] Mashhadi H., Rajabi J., Khorasani (2013). Price-takers bidding strategies in joint energy and spinning reserve 
pay-as-bid markets, Iranian Journal of Electrical and Electronic Engineering, Vol. 9, No. 1.

[26] Yamin H. (2005). Spinning reserve uncertainty in dayahead competitive electricity markets for gencos, IEEE Transactions on Power Systems, Vol. 20, No. 1, pp. 521-523.

[27] Mashhour E., Moghaddas-Tafreshi S. (2011). Bidding strategy of virtual power plant for participating in energy and spinning reserve markets 2014; parti: Problem formulation, IEEE Transactions on Power Systems, Vol. 26, No. 2, pp. 949-956.

[28] Soltani M., Raoofat M., Rostami M. (2012). Optimal reliable strategy of virtual power plant in energy and frequency control markets, Proceedings of 17th Conference on Electrical Power Distribution Networks (EPDC), pp. 1-6.

[29] Shi L., Luo Y., Tu G. (2014). Bidding strategy of microgrid with consideration of uncertainty for participating in power market, International Journal of Electrical Power and Energy Systems, Vol. 59, pp. 113.

[30] Narimani I., Goldani S. (2015). Participating of microgrids in energy and spinning reserve markets intra-day market, International Journal of Smart Electrical Engineering, Vol. 4, pp. 19-21.

[31] Ferruzzi G., Graditi G., Rossi F., Russo A. (2015). Optimal operation of a residential microgrid: The role of demand side management, Intelligent Industrial Systems, Vol. 1, No. 1, pp. 61-82.

\section{NOMENCLATURE}

Sets
$\Omega_{C}$
$\Omega_{B}$
$\Omega_{G}$
$\Omega_{D_{S E}}$
$\Omega_{D_{S T}}$
$\Omega_{D_{t h}}$
$\Omega_{D_{F}}$
$\Omega_{D_{S H}}$
$\Omega_{D_{C U}}$

\section{Variables}

$$
\begin{aligned}
& P_{C e_{t, j}}^{e} \\
& P_{C e_{t, j}}^{r} \\
& P_{G_{t, j}}^{e} \\
& P_{G_{t, j}}^{r} \\
& P_{B_{t, j}}
\end{aligned}
$$

Set Of Cogeneration (CHP) Power Plants Set Of Boilers

Set Of Only Electricity Production Plants

Set Of Electric Storage Units

Set Of Thermal Storage Units

Set Of Thermal Loads

Set Of Fixed Electrical Loads

Set Of Shiftable Electrical Loads

Set Of Curtailable Electrical Loads

Electric Power Of The $j_{t h}$ CHP

Unit For The Energy Market

Electric Power Of The $j_{t h}$ CHP

Unit For The Spinning Reserve Market

Power Of The $j_{t h}$ Generation Unit

For The Energy Market

Power Of The $j_{t h}$ Generation Unit

For The Spinning Reserve

Thermal Power Of The $j_{t h}$ Boiler

$$
\begin{aligned}
& P_{S E_{t, j}} \\
& P_{S T_{t, j}} \\
& W_{S E_{t, j}} \\
& W_{S T_{t, j}} \\
& P_{g r i d_{t}}^{e} \\
& P_{g r i d_{t}}^{r} \\
& P_{D_{C U_{t, j}}}^{e} \\
& P_{D_{C U_{t, j}}^{r}}^{r} \\
& D_{S H_{t, j}} \\
& P_{D_{S H_{t, j}}} \\
& u_{t, j}
\end{aligned}
$$

\section{Parameters}

$$
\begin{aligned}
& \rho_{t}^{e} \\
& \rho_{t}^{r} \\
& r_{t}
\end{aligned}
$$

\section{Energy Market Price}

Spinning Reserve Market Price Perceived Probability That Reserve Is Called Or Not

\section{Data}

$P_{D_{F t, j}}$

$$
P_{D_{t h}, j}
$$$$
\eta_{j}
$$$$
k_{s j}
$$$$
S_{j}
$$$$
s_{t}
$$$$
T_{j}
$$$$
T_{j}^{s t}
$$

\section{Function}

$$
\begin{aligned}
& C_{C_{j}}(\cdot) \\
& C_{G_{j}}(\cdot) \\
& C_{B_{j}}(\cdot) \\
& C_{D_{C U}}(\cdot) \\
& \mathrm{E}(\cdot)
\end{aligned}
$$

Power Of The $j_{t h}$ Electrical Fixed Load At $t_{t h}$ Hour Reduced By The Amount Of Electric RES Forecasted Power Of The $j_{t h}$ Thermal Load At $t_{t h}$ Hour Reduced By The Amount Of Thermal RES

Forecasted

Cogeneration Ratio

Charge/Discharge Thermal

Efficiency Coefficient

Cycle Duration Of The $j_{t h}$

Shiftable Load

Hourly Interval Of $\mathrm{Sj}$

Time Window Of The $j_{t h}$ Shiftable Load

Time At Which The $j_{t h}$ Shiftable Load Starts

Production Cost Of The $j_{t h}$ Cogeneration Unit

Production Cost Of The $j_{t h}$

Generation Unit

Production Cost Of The $j_{t h}$ Boiler

Curtailment Cost Of The $j_{t h}$ Load

Expected Value Of Generic Quantity x 